\title{
DESEMPENHO VEGETATIVO E REPRODUTIVO DA PINHEIRA (Annona squamosa L.) EM FUNÇÃO DE DIFERENTES COMPRIMENTOS DE RAMOS PODADOS ${ }^{1}$
}

\author{
NILMA OLIVEIRA DIAS², IVAN VILAS BÔAS SOUZA³, JOSÉ CARLSON GUSMÃO DA SILVA³, KATIANE SANTIAGO \\ SILVA ${ }^{3}$, MARINÊS PEREIRA BOMFIM ${ }^{4}$, JEAN FARLEY TEIXEIRA ALVES ${ }^{4}$, TIYOKO NAIR HOJO REBOUÇAS ${ }^{5}$, \\ ANSELMO ELOY SILVEIRA VIANA ${ }^{5}$, ABEL REBOUÇAS SÃO JOSÉ 5
}

\begin{abstract}
RESUMO-O objetivo do presente estudo foi avaliar a influência exercida por diferentes comprimentos de ramos podados no crescimento vegetativo e reprodutivo da pinheira. O experimento foi conduzido no período de 21-02 a 1-07-2003, no município de Anagé, região de clima semi-árido do Estado da Bahia. O delineamento experimental foi em blocos casualisados, com seis tratamentos, quatro repetições e três plantas úteis por parcela. Os tratamentos utilizados foram: T1- ramos podados com $5 \mathrm{~cm}$ de comprimento; T2- ramos podados com $10 \mathrm{~cm}$ de comprimento; T3- ramos podados com $15 \mathrm{~cm}$ de comprimento; T4- ramos podados com $20 \mathrm{~cm}$ de comprimento; T5- ramos podados com $25 \mathrm{~cm}$ de comprimento; T6- ramos podados com 30 cm de comprimento. Constatou-se, nas condições estudadas, que ramos podados com menores comprimentos tendem a reduzir a emissão de flores e a aumentar o vigor de brotações e tamanho de frutos.
\end{abstract}

Termos para indexação: pinha, produção, indução floral.

\section{VEGETATIVE AND REPRODUCTIVE PERFORMANCE OF CUSTARD APPLE (Annona squamosa L.) ACCORDING TO DIFFERENT PRUNING BRANCHES LENGTHS}

\begin{abstract}
The objective of the present study was to evaluate the influence of pruning with different branches lengths on vegetative and reproductive growth of custard apple. The experiment was carried out from February $21^{\text {st }}$ to July $01^{\text {st }}, 2003$ in Anagé town, Bahia State, Brazil. The experimental design was randomized blocks, four replications and three plants per plot. The used treatments were: T1- branches pruned with $5 \mathrm{~cm}$ length; T2- branches pruned with $10 \mathrm{~cm}$ length; T3-branches pruned with $15 \mathrm{~cm}$ length; T4- branches pruned with $20 \mathrm{~cm}$ length; T5- branches pruned with $25 \mathrm{~cm}$ length; T6- branches pruned with $30 \mathrm{~cm}$ length. The obtained results showed that under the studied conditions, smaller branches pruning lengths reduced emission of flowers and increased characteristics of branches and fruits growth.
\end{abstract}

Index terms: custard apple, production, flower induction.

\section{INTRODUÇÃO}

Tipicamente de clima tropical e pertencente à família Annonaceae, a pinheira (Annona squamosa L.) é uma das espécies do gênero Annona de maior expressão econômica no Brasil. Também conhecida como ateira ou fruteira-do-conde, é importante em vários Estados brasileiros do Nordeste e do Sudeste. Sua exploração está relacionada principalmente ao comércio de fruta fresca nas centrais de abastecimento das diversas cidades do País. Também é explorada em nível de subsistência, de maneira extrativista, em pequenos pomares, sem que sejam adotadas técnicas apropriadas de manejo. Neste caso, a produtividade e a qualidade dos frutos são baixas e a comercialização é feita em feiras livres, às margens de rodovias, etc.

Como outros produtos agrícolas, a pinha é vendida a preços que oscilam ao longo do ano, dependendo da oferta. No segundo semestre do ano, época de entressafra, os preços tendem a ser mais compensadores.

A poda, com desfolha de ramos, pode controlar a época do florescimento de plantas de pinha e atemóia, pois as flores surgem sempre nas novas brotações vegetativas. A remoção de folhas é utilizada para a quebra de dormência das gemas vegetativas (Lemos et al., 2003). Segundo São José (1997), a poda de produção vem sendo praticada para produção na entressafra. Na região de clima semi-árido de Petrolina, em Pernambuco, a pinheira é podada com êxito entre os meses de maio e agosto com o objetivo de obter frutos no período de menor oferta no mercado brasileiro. No Estado de São Paulo, onde as temperaturas são inferiores, as podas são evitadas nos meses mais frios devido à redução no pegamento dos frutos.

O presente trabalho teve como objetivo aprimorar a técnica da poda de produção. Para tanto, buscou-se avaliar os comprimentos de ramos podados mais adequados para melhores desempenhos vegetativo e reprodutivo da planta e conseqüente obtenção de frutos de qualidade.

\section{MATERIAL E MÉTODOS}

O experimento foi implantado na Fazenda Rancho Alegre, localizada a $14^{\circ} 26^{\prime}$ de latitude sul e $41^{\circ} 04^{\prime}$ de longitude oeste de Greenwich, com 335 m de altitude, no município de Anagé, Sudoeste da Bahia. O clima é classificado como semi-árido com vegetação típica de caatinga, apresentando temperatura média anual de $22,3^{\circ} \mathrm{C}$ e precipitação pluviométrica média de $656 \mathrm{~mm} / \mathrm{ano}$.

Utilizou-se um pomar comercial de pinheiras, com cinco anos de idade, proveniente de sementes, que apresentavam em média $3,00 \mathrm{~m}$ de altura; 3,00 m de diâmetro de copa e 8,00 cm de diâmetro de tronco a $0,20 \mathrm{~m}$ acima do solo, estando dispostas em espaçamento 6,5 x 3,6 m e irrigadas por microaspersão, com 30 litros de água/hora, por 3,0 horas diárias. Durante o período experimental, as plantas avaliadas receberam 30 litros de esterco de curral curtido por planta no início da condução do experimento e adubações de cobertura, com uréia e cloreto de potássio, aplicados na projeção da copa em intervalos de 20 dias.O controle das plantas invasoras foi feito com aplicação do herbicida Paraquat na linha e a utilização de roçadeira nas entrelinhas. Durante os meses do experimento, foram realizadas as pulverizações necessárias ao controle da broca do ponteiro e dos frutos, com inseticidas.

A condução do experimento ocorreu no período de 21 de fevereiro, data de realização da poda, a $1^{\circ}$ de julho de 2003 , início da colheita. Utilizouse o delineamento experimental em blocos casualizados, com seis tratamentos, quatro repetições e parcelas constituídas por três plantas úteis. Os tratamentos foram definidos como: T1-ramos podados com $5 \mathrm{~cm}$

\footnotetext{
${ }^{1}$ (Trabalho 035/2004). Recebido: 22/04/2004. Aceito para publicação: 28/10/2004.

${ }^{2}$ Eng $^{\mathrm{a}}$. Agr ${ }^{\mathrm{a}}, \mathrm{M}_{\mathrm{Sc}}$, Universidade Estadual do Sudoeste da Bahia, Estrada do Bem Querer, Km 04, Caixa Postal 95, Vitória da Conquista - BA. Fone: (77) 424 8632. Email: nodias@terra.com.br

${ }^{3}$ Eng $^{\circ}$. Agr ${ }^{\circ}$, Mestrando em Agronomia, Universidade Estadual do Sudoeste da Bahia, Estrada do Bem Querer, Km 04, Caixa Postal 95, Vitória da Conquista- BA. Fone: (77) 424 8731. E-mail: mestrado.agronomia@uesb.br

${ }^{4}$ Discente do curso de Agronomia da Universidade Estadual do Sudoeste da Bahia, Estrada do Bem Querer, Km 04, Caixa Postal 95, Vitória da Conquista- BA. Fone: (77) 4218632 .

${ }^{5}$ Eng $^{\text {. }}$. Agr ${ }^{\circ}$., Dr., Universidade Estadual do Sudoeste da Bahia, Estrada do Bem Querer, Km 04, Caixa Postal 95, Vitória da Conquista - Ba. CEP 45083-900, E-mail: Abelsj@uesb.br
} 
de comprimento; T2- ramos podados com $10 \mathrm{~cm}$ de comprimento; T3ramos podados com $15 \mathrm{~cm}$ de comprimento; $\mathrm{T} 4$ - ramos podados com 20 cm de comprimento; T5- ramos podados com $25 \mathrm{~cm}$ de comprimento; T6Ramos podados com $30 \mathrm{~cm}$ de comprimento.

As podas foram efetuadas com tesoura de poda. Após o corte, as partes remanescentes dos ramos foram desfolhadas manualmente.

Para avaliações posteriores, em cada planta, foram marcados ao acaso cinco ramos podados que possuíam entre 10 e $12 \mathrm{~mm}$ de diâmetro (totalmente lignificados), totalizando 15 ramos por parcela. Por ocasião da antese, realizou-se a polinização artificial com pincel.

A coleta de dados iniciou-se 18 dias após a emissão das primeiras brotações (28 dias após a poda). Nos ramos previamente identificados, realizaram-se a contagem de gemas brotadas e o número de botões florais emitidos.

Aos 33 dias após a polinização, foi realizado o desbaste manual dos frutos, deixando-se em média 17 frutos por planta, bem distribuídos ao redor da copa.

Após 130 dias da realização da poda, foi medido o comprimento das brotações dos ramos podados

O peso, comprimento e diâmetro médios dos frutos foram determinados em seis frutos por parcela, colhidos ao acaso após atingir o estádio de maturação fisiológica (ponto de colheita), determinado pelo afastamento dos carpelos e coloração verde-amarelada dos tecidos intercarpelares. Os frutos foram pesados individualmente em balança analítica de precisão $(0,1 \mathrm{~g})$ e as medidas tomadas com auxílio de paquímetro.

Amostras de frutos (seis por parcela) foram colhidas ao acaso para realização de análises físicas. Após atingir o ponto de consumo, os frutos foram partidos manualmente, e as partes foram separadas para a obtenção dos seguintes dados: 1- peso da casca; 2- peso da semente; 3 peso da polpa; 4- peso do talo central; 5- número de sementes.

Os dados obtidos foram submetidos à análise estatística, utilizando-se do Sistema de Análises Estatísticas e Genéticas (SAEG) Foram realizadas as análises de variância e de regressão.

\section{RESULTADOS E DISCUSSÃO}

Decorridos 10 dias da poda de produção, os ramos de todos os tratamentos apresentaram brotação uniforme, estimulada pela remoção das folhas, com o surgimento dos botões florais juntamente aos brotos. A antese ocorreu 23 dias após a emissão das brotações, o que resultou no intervalo de 33 dias da poda à antese (Tabela 1). Este intervalo foi mais curto do que os encontrados por Silva et al. (2001) e Dias et al. (2003) que foram, respectivamente, de 45 dias para a poda realizada em 31 de maio e de 44 dias para a poda realizada em 21 de junho, também em condições de clima semi-árido do Sudoeste da Bahia.

Independentemente dos comprimentos dos ramos podados, constatou-se que da antese à maturação fisiológica dos frutos (colheita) decorreram 97 dias, totalizando-se 130 dias da poda à colheita (Tabela 1). Segundo Kavati (1997), para as condições do Estado de São Paulo, decorrem de 110 a 120 dias da antese ao amadurecimento dos frutos, podendo ser este período prolongado em caso de florescimento tardio. Entretanto, Silva (2000) encontrou, no município de Caraíbas-BA, intervalos de 120; 117 e 101 dias da antese à colheita para plantas podadas nos meses de maio, julho e setembro, respectivamente.

A duração do período ocorrido entre a poda de produção e a colheita pode ser influenciada por uma série de fatores, dentre os quais se

TABELA 1 - Número de dias para cada intervalo de estádios de desenvolvimento da pinheira após a poda de produção com diferentes comprimentos de ramos. Anagé-BA, 2003.

Intervalos dos estádios de desenvolvimento $\quad \mathbf{N}^{\circ}$ de dias

Da poda de produção até a brotação das gemas 10

com botões florais

Da brotação das gemas com botões florais até a antese

Da poda até a antese

$\mathrm{Da}$ antese até a maturação fisiológica dos frutos

97

Da poda até a maturação fisiológica dos frutos destacam: características climáticas, época do ano, vigor e estado nutricional da planta, irrigação, dentre outros manejos adotados.

Os ramos podados em diferentes comprimentos não influenciaram significativamente no número de gemas brotadas aos 28 dias após a poda (Tabela 2). De maneira geral, observou-se baixa emissão de ramos produtivos em gemas localizadas na porção inferior dos ramos podados. Estes resultados são semelhantes aos encontrados por Lemos et al. (2003) em plantas de atemóia (A. cherimola Mill. x A. squamosa $\mathrm{L}$.), das quais brotaram 4,88 gemas em média, também próximas ao local da poda.

TABELA 2 - Médias do número de brotações por ramo emitidas 28 dias após a poda e comprimento das brotações aos 130 dias após a poda. Anagé-BA, 2003.

\begin{tabular}{lc}
\hline \multicolumn{1}{c}{ Tratamentos } & $\mathbf{N}^{\circ}$ de brotações \\
\hline T1- ramos com 5 cm de comprimento & 3,13 \\
T2- ramos com 10 cm de comprimento & 3,91 \\
T3- ramos com 15 cm de comprimento & 3,65 \\
T4- ramos com 20 cm de comprimento & 4,30 \\
T5- ramos com 25 cm de comprimento & 3,80 \\
T6- ramos com $30 \mathrm{~cm}$ de comprimento & 3,88 \\
CV $(\%)$ & 18,42 \\
\hline
\end{tabular}

A análise de regressão para o comprimento das brotações demonstrou efeito linear decrescente, ou seja, quanto mais curta a porção remanescente do ramo podado, maior o tamanho alcançado pelas brotações provenientes dos mesmos, conforme se observa na Figura 1. De acordo com um dos princípios que regem a poda, apresentados por Piza Júnior (1994) e Simão (1998), quanto mais severa for a poda, maior será o vigor da brotação resultante. Piza Júnior (1994) ainda explica que esse efeito pode ocorrer devido à maior disponibilidade relativa de nitrogênio acumulado pela planta na porção mais velha de seus ramos, bem como pela maior quantidade disponível de reservas acumuladas em ramos, tronco e raízes, para os pontos que permanecem na planta após a operação.

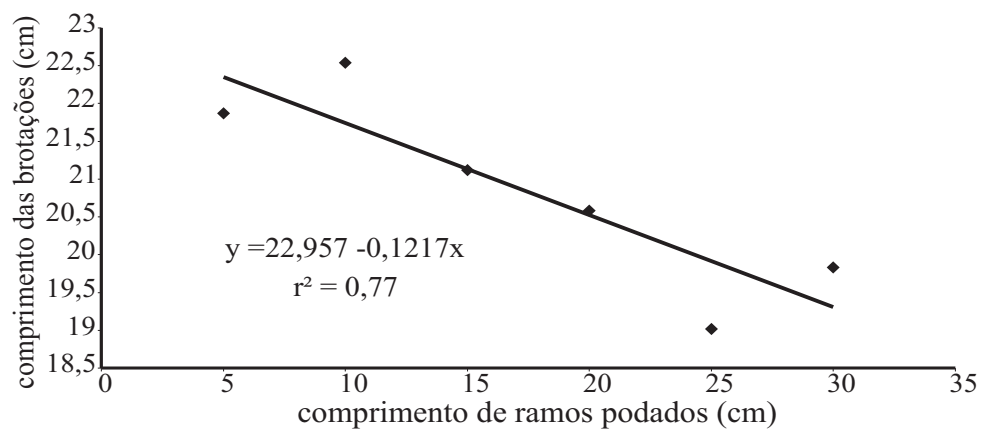

FIGURA 1 - Comprimento das brotações, em função do comprimento de ramos podados. Anagé-BA, 2003.

Observou-se efeito significativo dos comprimentos de ramos podados sobre o número médio de botões florais emitidos por ramo. A análise de regressão para essa característica demonstrou efeito linear crescente à medida que se aumenta o comprimento dos ramos podados (Figura 2). Um dos fatores que influenciam na indução floral é uma relação favorável carbono/proteína (Larcher, 2000). Segundo Piza Júnior (1994), durante o período de repouso, as plantas armazenam fotossintatos predominantemente nos tecidos jovens, existentes nas extremidades dos ramos, enquanto a disponibilidade de nitrogênio é maior nos tecidos mais velhos, que se encontram na sua base. Por essa razão, a relação carbono/ nitrogênio $(\mathrm{C} / \mathrm{N})$ nos tecidos próximos à gema apical é bastante elevada, dando origem a um crescimento pouco vigoroso e muito fértil. Quanto mais severo for o encurtamento feito em um ramo, mais estreita será a relação $\mathrm{C} / \mathrm{N}$ nos tecidos próximos à gema na posição terminal, razão pela qual esse crescimento é mais vigoroso e menos frutífero.

É importante enfatizar que o número de flores emitidas pode variar em função de fatores climáticos, práticas culturais, dentre outros.

Quanto às características de comprimento e diâmetro, verificouse através da análise de regressão uma resposta linear decrescente em 


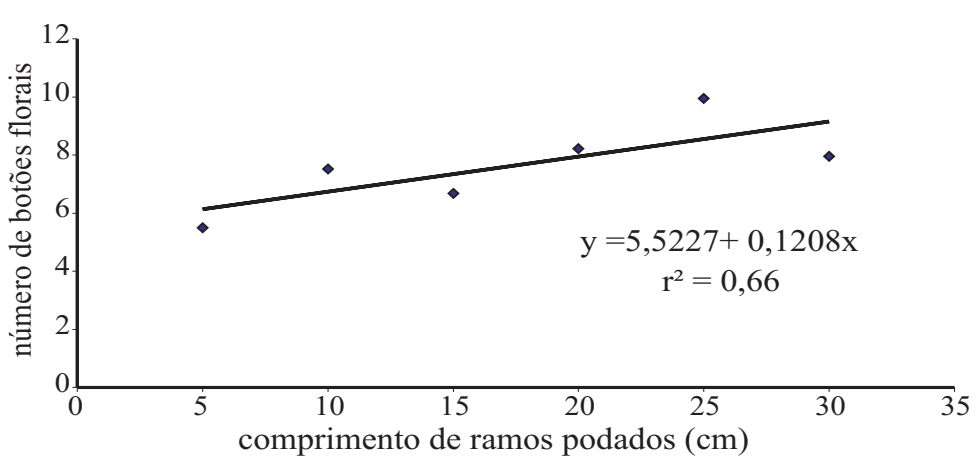

FIGURA 2 - Número de botões florais emitidos por ramo, em função do comprimento de ramos podados. Anagé-BA, 2003.

função dos comprimentos de poda adotados nos tratamentos (Figuras $3 \mathrm{e}$ 4). Com base no princípio fisiológico, de que quanto mais severa a poda, maior o vigor da brotação resultante (Piza Júnior., 1994; Simão, 1998), como foi constatado no presente estudo, pode-se presumir que as brotações maiores, formadas à medida que se reduziu o comprimento dos ramos podados (Figura 1), foram os aspectos responsáveis pela produção de frutos mais vigorosos por tratamentos com podas mais curtas. Nesse sentido, supõe-se que, na medida em que o encurtamento da poda originou brotos com menor número de flores, diminuiu-se também a competição por fotoassimilados requeridos, o que pode explicar a ocorrência de frutos mais desenvolvidos, na medida em que se reduziu o comprimento de poda.

Não houve efeito significativo do comprimento de ramos podados sobre peso da casca, peso da polpa, peso das sementes, número de sementes e peso do talo central (Tabela 3). Pereira et al. (2003) encontraram médias de: $125,0 \mathrm{~g}$ para o peso da casca; $142,5 \mathrm{~g}$ para o peso da polpa; $25,9 \mathrm{~g}$ para o peso de sementes e 68,7 para o número de sementes. As variações observadas entre diferentes estudos podem ser explicadas pelas condições ecofisiológicas particulares e pelo material genético.

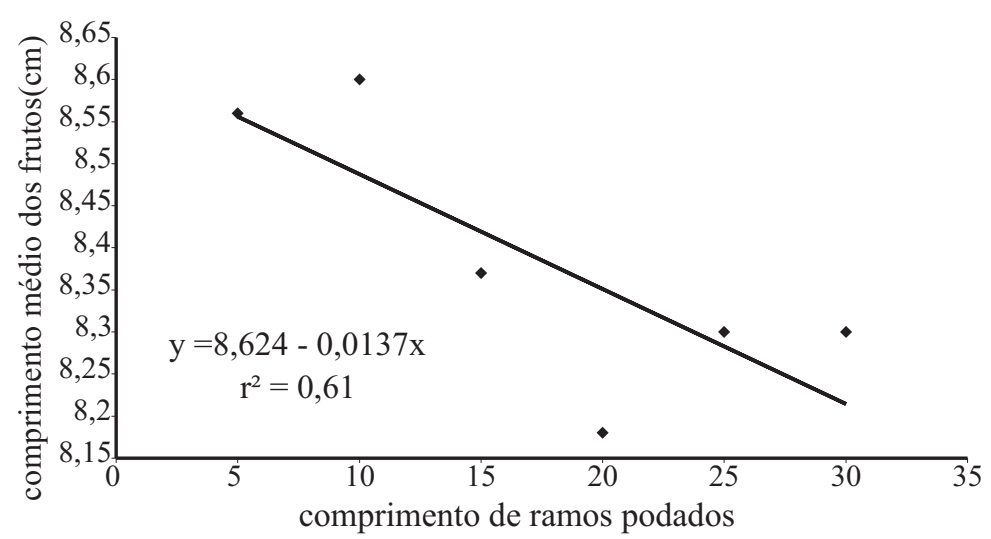

FIGURA 3 - Comprimento médio dos frutos (cm), em função do comprimento de ramos podados. Anagé-BA, 2003

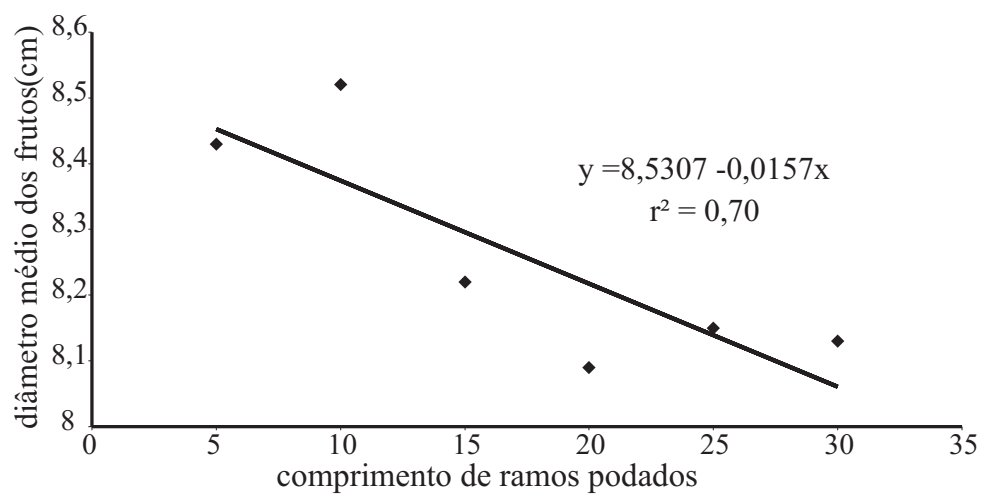

FIGURA 4 - Diâmetro médio dos frutos (cm), em função do comprimento de ramos podados. Anagé-BA, 2003

TABELA 3 - Valores médios do peso da casca (PC), peso da polpa (PP), peso das sementes (PS), número de sementes (NS) e peso do talo central (PT) de frutos de pinheiras podadas a diferentes comprimentos de ramos. Anagé - BA, 2003.

\begin{tabular}{|c|c|c|c|c|c|}
\hline $\begin{array}{rr}\text { Tratamentos } \\
\end{array}$ & PC (g) & PP (g) & PS (g) & $\mathbf{N S}$ & PT (g) \\
\hline $\mathrm{T} 1$ - ramos com $5 \mathrm{~cm}$ de comprimento & 116,3 & 93,4 & 28,2 & 72,3 & 4,6 \\
\hline $\mathrm{T} 2$ - ramos com $10 \mathrm{~cm}$ de comprimento & 125,1 & 95,4 & 31,6 & 80,9 & 4,8 \\
\hline $\mathrm{T} 3$ - ramos com $15 \mathrm{~cm}$ de comprimento & 119,8 & 82,5 & 28,1 & 72,7 & 4,1 \\
\hline $\mathrm{T} 4$ - ramos com $20 \mathrm{~cm}$ de comprimento & 99,8 & 88,6 & 29,0 & 79,2 & 4,0 \\
\hline T5 - ramos com $25 \mathrm{~cm}$ de comprimento & 106,7 & 85,1 & 27,2 & 71,5 & 4,3 \\
\hline T6 - ramos com $30 \mathrm{~cm}$ de comprimento & 111,2 & 90,2 & 27,4 & 72,6 & 4,1 \\
\hline
\end{tabular}

\section{CONCLUSÕES}

1) Para as condições edafoclimáticas em que o presente trabalho foi desenvolvido, concluiu-se que ramos podados com menores comprimentos tendem a produzir menor número de flores, brotações mais vigorosas e frutos de maior tamanho, não havendo influência sobre o peso da casca, peso da polpa, peso e número de sementes dos frutos.

2) A influência exercida no desempenho vegetativo e reprodutivo da planta indica a necessidade de uma escolha criteriosa do comprimento de ramos adotados na poda de produção, considerando-se os aspectos de manejo, idade, genótipo e condições edafoclimáticas do cultivo.

\section{REFERÊNCIAS}

DIAS, N. O.; MATSUMOTO, S. N.; REBOUÇAS, T. N. R.; VIANA, A. E. S.; SÃO JOSÉ, A. R.; SOUZA, I. V. B. Influência da poda de produção em ramos de diferentes diâmetros no desenvolvimento vegetativo e reprodutivo da pinheira. Revista Brasileira de Fruticultura, Jaboticabal, v.25, n.1, p.100-103, 2003.

KAVATI, R. Embalagem e comercialização. In: SÃO JOSÉ, A. R.; SOUZA, I. V. B.;MORAIS. O. M.; REBOUÇAS, T. N. H. Anonáceas: produção e mercado. Vitória da Conquista: UESB/DFZ, 1997. p.257-262.

LARCHER, W. Ecofisiologia vegetal. São Carlos: Rima, 2000. 531p.
LEMOS, E. D. P. de; MARINHO, G. de A.; ALMEIDA, M. C. Efeito da desfolha de ramos sobre a indução de brotos e flores em atemóia (Annona cherimola Mill $x$ Annona squamosa L.) Revista Brasileira de Fruticultura, Jaboticabal, v. 25, n. 1, p. 170-171, 2003.

PEREIRA, M. C. T. P.; NIETSCHE, S. ; SANTOS, F. S.; XAVIER, A.; CUNHA,L. de M. V. da; NUNES, C. F.; SANTOS. F. M. Efeito de horários de polinização artificial no pegamento e qualidade de frutos de pinheira (Annona squamosa L.). Revista Brasileira de Fruticultura, Jaboticabal, v. 25, n. 2, p. 203-205,. 2003.

PIZA JUNIOR, C. T. A poda da goiabeira de mesa. Campinas: CATI, 1994, 30p. (Boletim Técnico, 222)

SÃO JOSÉ, A. R. Aspectos generables de las anonáceas en Brasil. In: CONGRESSO INTERNACIONAL DE ANONACEAS, 1997, Chapingo, México. Memórias... Chapingo: Universidad Autónoma de Chapingo. 1997. p. 92-103.

SILVA, A.C.da. Épocas de poda e métodos de polinização na produção da pinheira (Annona squamosa L.). 2000. 101f. Tese (Mestrado em Fruticultura) - Escola de Agronomia, Universidade Federal da Bahia, Cruz das Almas, 2000.

SILVA, A. C. da; SÃO JOSÉ, A. R.; VIANA, A. E. S. Efeito de métodos de polinização no pegamento de frutos e na produção da pinheira. Magistra, Cruz das Almas, v.13, n. 2. p. 73-76, 2001.

SIMÃO, S. Tratado de fruticultura. Piracicaba: FEALQ, 1998. 760p. 